\title{
Collecting neurophysiological data to investigate users' cognitive states during game play
}

\author{
Patrick Charland \\ Département de didactique \\ Université du Québec à \\ Montréal \\ Montréal, Canada \\ charland.patrick@uqam.ca
}

\author{
Geneviève Allaire-Duquette \\ Université du Québec à \\ Montréal \\ Montreal, Canada \\ allaire- \\ duquette.genevieve@courrier. \\ uqam.ca
}

\author{
Pierre-Majorique Léger \\ Department of IT \\ HEC Montreal, \\ Montreal, Canada \\ pml@hec.ca
}

\begin{abstract}
This paper explores the potential of collecting neurophysiological data in order to further understand user's learning experience. The experimental setup involves collecting electroencephalographic signal (EEG) from the brain cortex to infer users' cognitive state while they played an educational video game designed to support the learning of Newtonian mechanics. Preliminary results suggest that this neuroscience perspective is quite promising in the idea of quantitatively characterizing users' learning experience. This could be an innovative and promising avenue in general game development or in educational videogame research field.
\end{abstract}

Keywords: EEG, cognitive state, educational video games, science education.

\section{INTRODUCTION}

In the field of scientific education, the foremost challenge is, and has been, addressing the gap between the misconceptions of students and scientific understanding of realities and phenomenon. Although a large body of research argues that interactive teaching methods are usually more effective in changing students' misconceptions than traditional lecture-based instruction [1], only a few researchers examined the impact on video games as a an emotionally engaging instructional approach.

Recently, disciplines, such as economics, psychology and marketing, have been very proactive in incorporating neurophysiological measurements e.g. [17-18-19-20], in order to assess learners' cognitive state, such as cognitive engagement [28-29-30]. In the educational video game (EVG) research field, several researchers are also bringing neurophysiologic tools to characterize player's experience. [see 30].

While many researchers generally consider engagement as playing a key-role in learning, measuring the learners' engagement remained a challenging task. Until now, researchers were using self-reported methods to measure engagement, but paradoxically it required to take the subject out of its very state of mind. Neurophysiologic tools are much less obstructive than traditional self-reported scales, and can allow for a more natural learning environment. These tools include equipments to monitor heart rate (EKG), the body temperature, the electrodermal activity (EDA), and the electroencephalography (EEG). The remaining of this paper focuses solely on this later technique. EEG signal was collected to classify player's cognitive states (sleepiness, distraction and engagement), thus examining his experience during game play.

\section{ASSESSING COGNITIVE STATES OF A LEARNER}

An active learner is energetically and emotionally involved, and plays a dynamic and self-motivated role in how and what needs to be learned [2]. A number of educators and researchers (see [3]) have found that EVGs improve learning through interactive exchanges and promote engagement from students. Since motivation and engagement are closely related concepts [4], consequently the recording of a real-time index on engagement provides accurate and valuable information about intrinsic motivation of players in action.

An engagement is a state of high alertness to task relevant stimuli [5-6]. As mentioned before, engagement have mostly been studied in computer game research field using psychometric scales in which subjects were asked to selfreport their level of engagement e.g.[7]. Since the 90's, some researchers began taking measurements of attention [10-1112] by using EEG ambulatory systems and presenting results for real time classification on the subject's cognitive state. There have been numerous studies quantifying visual alertness and attention using electroencephalography (EEG) measures [13], and measuring the efficiency of multi-modal interaction paradigms for virtual environments [10-14-15-16], but not much on users' engagement [8-9].

General EEG body of knowledge states that i) increases in brainwave beta activity are associated to a higher level of engagement related to a task, and ii), increases related to alpha 
and/or theta activity would reflect less alertness and task engagement due to decreased information processing [21]

Alongside, Pope et al. [22] developed and validated an Engagement Index (EI) from various scalp sites (respectively $\mathrm{Cz}, \mathrm{T} 5, \mathrm{P} 3, \mathrm{Pz}, \mathrm{P} 4,01,02$ and $\mathrm{Cz}, \mathrm{Pz}, \mathrm{P} 3, \mathrm{P} 4)$, and suggested that computing the measure of "beta / (alpha+theta)" reflects a task engagement index.

Since Pope's and his colleague work, new non-intrusive technologies and robust algorithms have been developed and validated e.g. [23]. In a very innovative perspective, it is now possible to precisely quantify cognitive states (sleepiness; distraction; low engagement; high engagement) from individuals within a specific task. These algorithms were initially developed in the research field of neuroergonomics, aiming to investigate drivers' or plane pilots' level of alertness. We hypothesize that these constructs could be useful when transferred to other fields, such as education.

\section{RESEARCH GOAL}

This article aims to present data recently collected from a exploratory study in science education. The research goal is to investigate if engagement measurements analyzed with recent neuroergonomics algorithms could be useful to characterize the learning experience of students playing an educational video game. Using an experimental approach, a within-subject comparison was done to determine cognitive state of learners during the game. In the context of this study, we are using an EVG called Mecanika, which support the learning of Newtonian mechanics.

Preliminary results from this study will be discussed within the perspective of their transferability to other fields like education or computer game industry. We hypothesize that the methodology used may contribute to develop more effective and engaging tasks and activities, such as educational video games.

\section{RESEARCH DESIGN}

EEG signal of twenty-four (24) subjects within an authentic learning environment was gathered during an approximately 10 minutes playing session. During this session, the subjects had to complete the most they could out of the five (5) levels available in the Mecanika game. All subjects were righthanded male adults, students in a business school IT program. None of the subjects had previous experience related to the game.

\section{A. Mecanika : an educational video game}

Mecanika doesn't require any calculation or use of formulas since the game is designed to learn about qualitative conceptual physics. The goal is to place robots (forces) and activate throwers in order to collect all stars by lighting them with collect-o-matics. However the collect-o-matics are not controlled directly by the students. Instead, they have to strategically place the robots, representing constant force, circular movement or change in gravity, to control the trajectory of the collect-o-matics. The trick is to visualize the trajectory the collect-o-matics have to take to light the stars and placing the robots accordingly to predictions, comprehension of active forces and in regard of the speed limit imposed in danger zones. Then, students can give it a try by activating the thrower. If the robots are correctly placed, collect-o-matics will collect every star and the student will have completed the level. If the collect-o-matics fail to light every star, the student is asked to try again by placing the robots differently. Figure 1 shows an example where the collect-o-matics fail to pass on the third star because the wind robot (represented by the empty rectangle) has only been used partially. To successfully complete this level, the wind zone has to be placed in a way that optimizes its influence on the trajectory of collect-omatics, in this case, right after the exit of the thrower (see figure 2). When placed like that, the collect-o-matics are accelerated on a sufficient distance to pass over the ramp and light all of the three stars.

The original game consists of 50 levels designed in coherence with the Force Concept Inventory (FCI), a robust validated questionnaire [24] developed in science education research field to assess students' qualitative understanding of basic concepts in Newtonian physics. Each level of Mecanika triggers a specific misconception identified in the FCI. In this pilot study, five (5) levels were extracted from the original game.

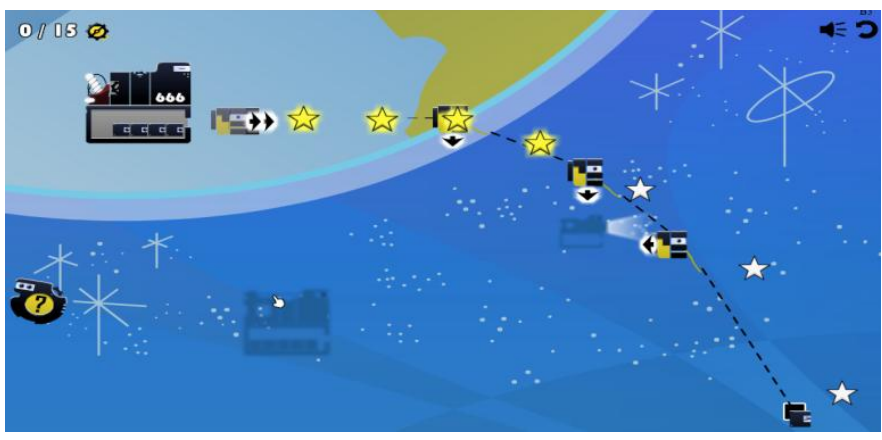

Figure 1. Mecanika game screen

\section{B. Instrumentation}

EEG signal was gathered using wireless B-Alert headset system, developed by Advanced Brain Monitoring, Inc.

The B-Alert sensor headset [25-26] was used to acquire the EEG data from three referential channels $(\mathrm{Fz}, \mathrm{Cz}$, and $\mathrm{POz}$ ) and two bipolar channels (Fz-POz and Cz-POz). The sampling rate was 256 units for all channels. Proprietary data acquisition software are stored the EEG data on the host computer. A cleaning algorithm [25] automatically detect and remove artifact in the time-domain EEG signal, including spikes 
caused by tapping or bumping of the sensors, amplifier saturation, and excursions that occur during the onset or recovery related to saturations. Eye blinks and excessive muscle activities were also identified and decontaminated by an automatic wavelet transform.

From the decontaminated EEG recording, signal is then analyzed on a second-by-second basis, and averaged on a one second time frame. In other words, the B-Alert algorithm classifies every seconds the subject's probability of being in one of the four cognitive states (sleep onset, distraction/relaxed wakefulness, low engagement, and high engagement) [27].

\section{Procedure}

Installation of B-Alert headset is a short procedure, which requires less than 10 minutes. In order to make sure that all the electrodes are in place, the software starts the protocol with a measurement of their impedance.

Then, each subject has to perform a standardized cognitive task to individually calibrate the B-Alert engagement metric. Results of psychological measurements during the game involve a comparison with this calibration.

Finally, in-game usage data (time spent on levels, number of scouts thrown) were also collected for each subject.

\section{RESULTS AND DISCUSSION}

Data shown in this section are just gathered and partially analyzed at the time of paper submission. Further analysis should complete the preliminary and mostly descriptive data presented here.

Graphic 1 shows the general mean of overal cognitive states of all 24 users playing mecanika. We can state that a 10 minutes spent in Mecanika is a rather engaging task, while some users still fell sleepiness and distraction at some points of the game.

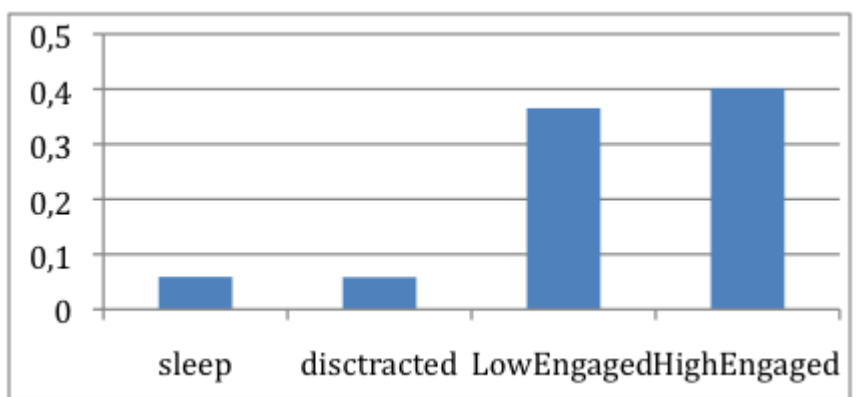

Graphic 1. Mean of overall cognitive state probablity during the game (all levels; $n=24$ )
On an individual analysis, graphic 2 is helpful in identifying sleepy or distracted users. On the $\mathrm{x}$ axis, we can observe each subject probability (y axis) of being in one of the four cognitive states. For example, Subject 4 was highly engaged in more than $80 \%$ of the game, but subject 17 seemed to be sleepy, and subject 23 was quite distracted.

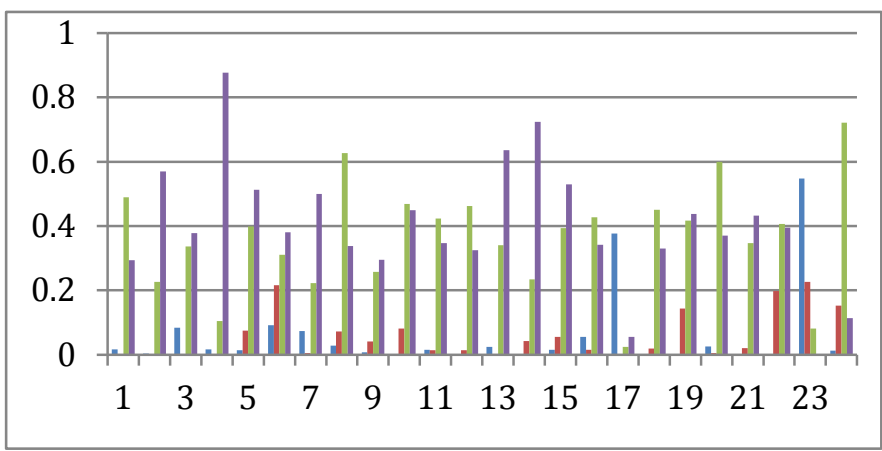

Graphic 2. Mean of the overall probability of cognitive states for each subjects

Legend : sleepy (blue)-distracted (red)-low engaged (green) high engaged (purple)

On a game level analysis, building upon the recent work of Senecal and his colleagues [31], an EEG index was also computed using the probability of the subject being in one of the four cognitive states :

\section{Prob High engagement + Prob Low engagement Prob Low engagement + Prob (Sleepy)}

The higher the index, the more cognitively engaged was the subject during the task. The EEG index was normalized using Level 1 of the game as a baseline. Graphic 3 report the variation of this index from the baseline.

We observe that the EEG index increased by $87,6 \%$ between the level 1 and 2 of the game meaning that the subjects had to mobilize their cognitive resources in order to solve the level 2 . This variation from baseline significantly reduces (Wilcoxon test, $\mathrm{p}=0.03$ ) between level 2 and level 3, with a 42,3\% difference with baseline. In level 4, subjects were almost back to their baseline level with a modest $17.4 \%$ difference. 


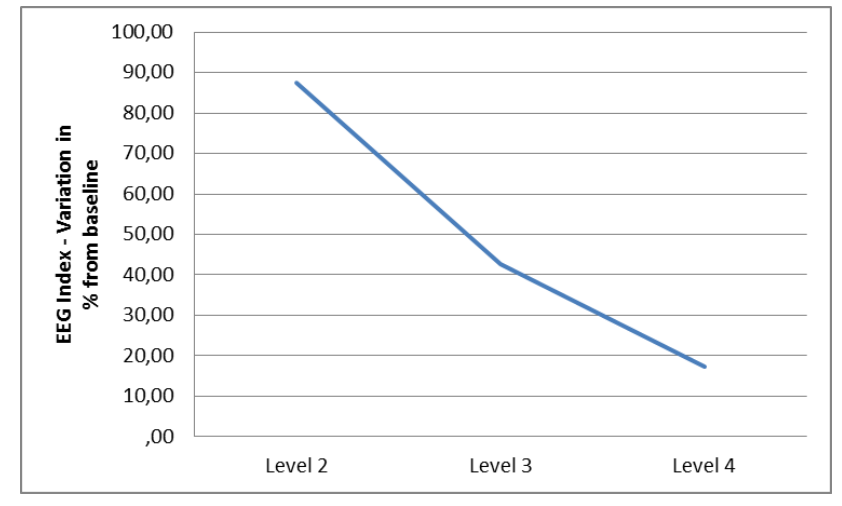

Graphic 3. Level by level variation of EEG Index from baseline (in \%)

These last results show that, as the game progresses, the learner become more skilled and required to mobilize less cognitive resources to solve the problems. This in line with recent work in cognitive neuroscience [32,33], which states that a dual process governs human decision and behavior: a more controlled system that is conscious, serial and slow, and a more automatic, which is unconscious, paralleled and effortless. As an expertise in a task is developed, one moves from a controlled system to an automatic system, thus changing the pattern of neuronal activations [34].

With analyzed data gathered so far, the observed wide variance of cognitive states troughout the subjects and the time variation of engagement are quite encouraging in the idea of using these neuroergonomics algorithms in education. Further analysis of these results should be considered in the perspective of finding statistical relationships between performance in the game (usage data) and psychophysiologic data.

\section{CONCLUSION}

The objective of this exploratory study was primarily to investigate if new EEG analysis algorithms developed in the field of neuroergonomics could be transferred to other fields, such as research in science education or gaming. In parallel, the research protocol of this pilot study was to identify the challenge involved in to scaling up this investigation to a larger group of participants.

Our current results show that using neurophysiological tools like EEG could be a promising avenue in research in education. We humbly consider that real time measurement of cognitive state would represent a promising research application for game development. Bringing neurophysiologic tools within an educational video game setup could lead to a more objective measure of the efficiency in this specific instructional approach. Also it gives game developers the possibility to explore a player's experience and validate, for example, a game's sequence based on real time objective data.

Obviously, the small sample size, in the current study, limits the possibilities of generalization among our findings. Also, this research was limited to the study related to cognitive states, and we cannot report on the actual motivation or learning from the subjects, which will be part of an eventual scaled up study.

\section{REFERENCES}

[1] R. R. Hake, "Interactive-engagement vs Traditional Methods in Mechanics Instruction," American Journal of Physics, vol. 66, pp. 64-74, 1998.

[2] R. Pekrun, T. Goetz, W. Titz, and R. P. Perry, "Academic Emotions in Students' Self-Regulated Learning and Achievement: A Program of Qualitative and Quantitative Research," Educational Psychologist, vol. 37, pp. 91-105, 2002.

[3] J. Anderson and M. Barnett, "Using Video Games to Support PreService Elementary Teachers Learning of Basic Physics Principles," Journal of Science Education Technology, vol. 20, pp. 347-362, 2011.

[4] M. Ainley, "What do we know about student motivation and engagement?," presented at the Annual meeting of the Australian Association for Research in Education, Melbourne, Australia, 2004.

[5] F. Freeman, A. T. Mikulka, M. W. Scerbo, and L. Scott, "An evaluation of an adaptive automation system using a cognitive vigilance task," Biological Psychology, vol. 67, pp. 283-297, 2004.

[6] A. Gale and B. Christie, Psychophysiology and the electronic workplace: John Wiley \& Sons Inc, 1987.

[7] J. H. Brockmyer, C. M. Fox, K. A. Curtiss, E. McBroom, K. M Burkhart, and J. N. Pidruzny, "The development of the Game Engagement Questionnaire: A measure of engagement in video gameplaying," Journal of Experimental Social Psychology, vol. 45, pp. 624634, 2009.

[8] A. T. Pope and E. H. Bogart, "Method of encouraging attention by correlating video game difficulty with attention level," 1994.

[9] M. E. Smith, A. Gevins, H. Brown, A. Karnik, and R. Du, "Monitoring Task Loading with Multivariate EEG Measures during Complex Forms of Human-Computer Interaction," Human Factors: The Journal of the Human Factors and Ergonomics Society, vol. 43, pp. 366-380, 2001.

[10] C. Berka, D. J. Levendowski, P. Westbrook, G. Davis, M. N. Lumicao, R. E. Olmstead, M. Popovic, V. T. Zivkovic, and C. K. Ramsey, "EEG quantification of alertness: methods for early identification of individuals most susceptible to sleep deprivation," 2005, pp. 78-89.

[11] S. Makeig and T.-P. Jung, "Changes in altertness are a principal component of variance in the eeg spectrum," NeuroReport, vol. 7, pp. 213-217, 1995.

[12] M. B. Sterman and C. A. Mann, "Concepts and applications of EEG analysis in aviation performance evaluation," Biological psychology, vol. 40, pp. 115-130, 1995.

[13] A. Gevins and M. E. Smith, "Neurophysiologic measures for neuroergonomics," presented at the HCI International 2005, Las Vegas, NV, 2005.

[14] A. Daurat, A. Aguirre, J. Foret, P. Gonnet, A. Keromes, and O. Benoit, "Bright light affects alertness and performance rhythms during a 24-h constant routine," Physiology \&amp; Behavior, vol. 53, pp. 929-936, 1993

[15] S. Higuchi, Y. Motohashi, Y. Liu, and A. Maeda, "Effects of playing computer game using a bright display on presleep physiological variables, sleep latency, slow wave sleep and REM sleep," Journal of Sleep Research, vol. 14, pp. 267-273, 2005. 
[16] K. Kahol, J. French, S. Panchanathan, G. Davis, and C. Berka, "Evaluating the Role of Visio-Haptic Feedback in Multimodal Interfaces through EEG Analysis. ," in Augmented Cognition: Past, Present and Future, D. Schmorrow, K. Stanney, and L. Reeves, Eds., ed Arlington, VA: Strategic Analysis, 2006, pp. 290.

[17] M. D. Lieberman, "Social Cognitive Neuroscience: A Review of Core Processes," Annual Review of Psychology, vol. 58, pp. 259-289, 2007.

[18] C. F. Camerer, G. Lowenstein, and D. Prelec, "Neuroeconomics: How Neuroscience can Inform Economics," Journal of Economic Literature, vol. 38, pp. 9-64, 2005.

[19] P. Glimcher and A. Rustichini, "Neuroeconomics: The Consilience of Brain and Decision. ," Science, vol. 51, pp. 447-452, 2004

[20] P. Kenning and H. Plassmann, "NeuroEconomics: An Overview from an Economic Perspective," Brain Research Bulletin vol. 67, pp. 343-354, 2005.

[21] F. G. Freeman, P. J. Mikulka, L. J. Prinzel, and M. W. Scerbo, "Evaluation of an adaptive automation system using three EEG indices with a visual tracking task," Biological psychology, vol. 50, pp. 61-76, 1999.

[22] A. T. Pope, E. H. Bogart, and D. S. Bartolome, "Biocybernetic system evaluation indices of operator engagement in automated task," Biological psychology, vol. 40, pp. 187-195, 1995.

[23] R. Stevens, T. Galloway, C. Berka, and A. Behneman, "A Neurophysiologic Approach For Studying Team Cognition," in Interservice/Industry Training, Simulation, and Education Conference I/ITSEC, 2010.

[24] D. Hestenes, M. Wells, and G. Swackhamer, "Force Concept Inventory," The Physics Teacher, vol. 30, pp. 141-158, 1992

[25] C. Berka, D. J. Levendowski, M. N. Lumicao, A. Yau, G. Daivis, V. Zivkovic, R. E. Olmstead, P. D. Tremoulet, and P. L. Craven, "EEG Correlates of Task Engagement and Mental Workload in Vigilence, Learning and Memory Tasks," Aviation, Space and Environmental Medecine, vol. 78, 2007

[26] R. R. Johnson, D. P. Popovic, R. E. Olmstead, M. Stikic, D. J. Levendowski, and C. Berka, "Drowsiness/alertness algorithm development and validation using synchronized EEG and cognitive performance to individualize a generalized model," Biological psychology, vol. 87, pp. 241-250, 2011.

[27] M. Stikic, R. R. Johnson, D. J. Levendowski, D. P. Popovic, R. E. Olmstead, and C. Berka, "EEG-derived estimators of present and future cognitive performance," Frontiers in Human Neuroscience, vol. 5, 2011 August-5, pp.3-4, 2011.

[28] A. Drachen and L. Nacke, "Psychophysiological Correlations with Gameplay Experience Dimensions." Arxiv preprint arXiv:1004.0243, 2002

[29] R. Mandryk, and K. Inkpen, "Physiological indicators for the evaluation of co-located collaborative play", ACM, 2004

[30] L. Nacke, and C. Lindley, "Flow and immersion in first-person shooters: measuring the player's gameplay experience", Proceedings of the 2008 Conference on Future Play: Research, Play, Share, 2008.

[31] S. Senecal, P.-M. Léger, M. Fredette and R. Riedl, “Consumers' Online Cognitive Scripts: A Neurophysiological Approach" Proceedings of the 012 International Conference on Information Systems (ICIS 2012), December 16-19, 2012

[32] C. Camerer, G. Loewenstein, and D. Prelec, 2005. "Neuroeconomics: How Neuroscience Can Inform Economics," Journal of Economic Literature, vol 43, pp. 9-64, 2004.

[33] A.B. Satpute and M.D. Lieberman, "Integrating automatic and controlled processing into neurocognitive models of social cognition," Brain Research, vol 1079, pp. 86-9, 2006.

[34] N.M. Hill and W. Schneider, "Brain Changes in the Development of Expertise: Neuroanatomical and Neurophysiological Evidence about Skill-based Adaptations," In Cambridge Handbook of Expertise and Expert Performance, K.A. Ericsson, N. Charness, P. Feltovich, and R. Hoffman (eds.), Cambridge University Press. pp. 653-682, 2006.

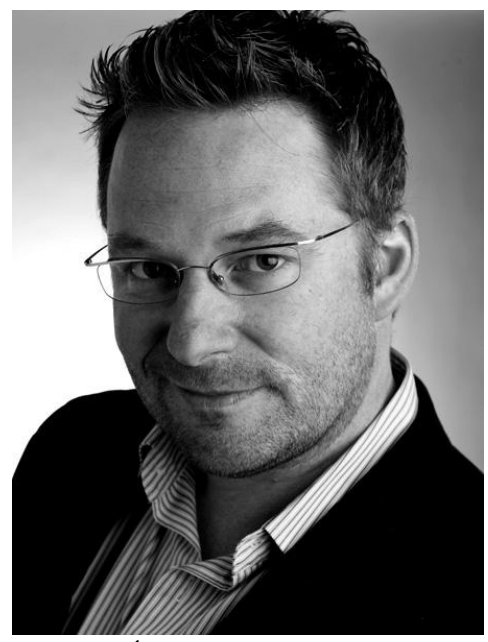

Prof. Patrick Charland, Ph.D., is associate professor in the department of didactics at Université du Québec à Montréal. $\mathrm{He}$ is specialized in science and technlogy education. His main research areas are science and technology teching practices, neuroeducation, environmental education, curriculum development and international education.

(Photo : Émilie Tournevache)

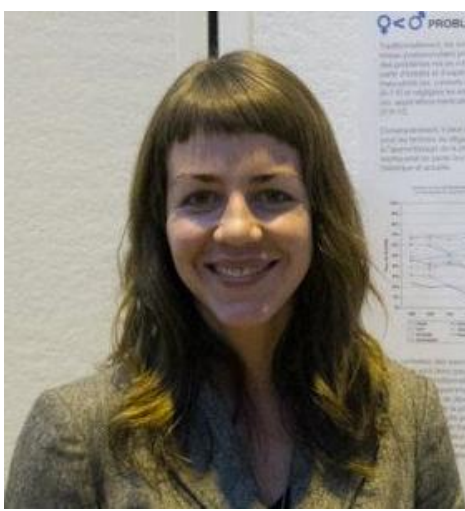

Genevieve AllaireDuquette is a lecturer in Education at Université du Québec à Montréal, where she received degree in Science Education. She specializes in the field of neuroeducation, studying the neurophysiological gender effect of problem contextualization.

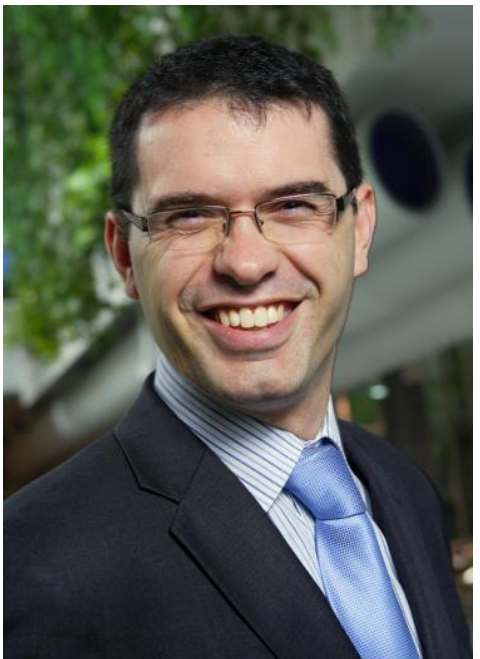

Prof. Pierre-Majorique Léger, Ph.D,. is full professor in information technologies at HEC Montréal, director of ERPsim Lab, and codirector of Tech3Lab. He holds a PhD in industrial engineering from Ecole

Polytechnique de Montréal. He is the principal inventor of ERPsim, a simulation game to teach ERP concepts, which is now used by hundreds of universities and many

Fortune 1000 organizations. 